\title{
FILOSOFIA DA ANCESTRALIDADE
}

(Resenha)

Flávia Damião*

\section{OLIVEIRA, Eduardo David de. Filosofia da Ancestralidade: Corpo e Mito na Filosofia da Educação Brasileira. Curitiba: Editora Gráfica Popular, 2007.}

Desde muito cedo entendi que a vida só é possivel re-inventada. Inventar mundos tornou-se meu ofício.

(OLIVEIRA, 2007, p.1)

Encantamento. Essa única palavra bastaria para definir o livro de Eduardo Oliveira - Filosofia da Ancestralidade: corpo e mito na filosofia da educação brasileira - fruto de sua tese de doutorado em Educação pela Universidade Federal do Ceará. Com o ofício de reinventar a vida, Eduardo Oliveira apresenta um ousado projeto conceitual: forjar uma filosofia da educação a partir da singularidade da experiência do corpo e do mito desde a cultura de matriz africana, acolhendo o que essa experiência tem de estrutura expansiva. A abordagem desses elementos centrais à obra é realizada num jogo regido por um pensamento que se move no universo de múltiplos e trinários. Um pensamento que tem no coletivo sua origem, existência e propagação. Daí resulta uma complexa rede de articulação e interconexão de conceitos, proposta pelo autor, tendo a ancestralidade como potente e propositor vetor filosófico para pensar a educação dos afrodescendentes brasileiros.

Assim, o livro é construído numa perspectiva de multiplicidade de áreas do conhecimento - filosofia, antropologia e educação. Elas estão imbricadas como numa teia de aranha. Uma teia magicamente produzida, na qual linhas paradigmáticas vindas de diferentes campos do saber se entrecruzam, se misturam, se enredam para constituir uma obra que com sabedoria propõe outros caminhos

\footnotetext{
" Pedagoga pela Universidade Federal da Bahia, UFBA, Especialista em Educação Infantil pela Universidade do Estado da Bahia, Mestre em Educação pela Universidade Federal do Ceará. Professora do Ensino Básico, Técnico e Tecnológico da UFBA, atuando na Creche. afrolfaviadamiao@gmail.com / flaviad@ufba.br

DAMIÃO, Flávia. Filosofia da ancestralidade (Resenha). Revista Sul-Americana de Filosofia e Educação. Número 18: maio-out/2012, p. 90-97.
} 
de produção de sentidos para filosofia da educação brasileira. Tudo isso é realizado sem perder de vista a beleza, a potência propositiva e o encantamento.

A produção do encantamento - acerca da alteridade, da ética, da filosofia e da educação - que o autor provoca no leitor é fruto da conjunção da sensibilidade de poeta, da inteligência implicada de pesquisador, do compromisso político do militante e da postura curiosa e questionadora de educador. ${ }^{1}$

Se junta a tudo isso a sua ancestralidade. Eduardo Oliveira é herdeiro de uma cultura que tem no mistério e no encantamento suas forças primordiais, a cultura de matriz africana. Como herdeiro dessa cultura ele assume o encanto como vetor de fazer ciência, como uma condição de estar na vida, como matéria prima para a (re)criação de mundos.

Assim, sob o regime do encantamento somos convidados a uma atitude criativa e compartilhada. Ele convida a criar juntos sentidos de realidades a partir de um universo de imagens, histórias, argumentos, experiências, reflexões, corporeidade, questionamentos, sensibilidades, diálogos, antropofagias...

Desde a primeira página do livro Eduardo Oliveira forja uma obra que não separa arte e ciência, e que faz dialogar forma e conteúdo. É por isso que logo no início encontramos um conto africano Tótemes. Nessa narrativa um pai apresenta para seu filho os valores e visão de mundo necessária a continuidade da existência do seu grupo.

Percorridas as páginas iniciais encontramos quatro grandes partes: Confissóes alvorescentes; Parte I: Do Movimento - Corpo; Parte II: De estruturas e singularidades - Mito; Itinerário de uma experiência.

Em Confissóes alvorescentes Eduardo Oliveira instiga o leitor a conhecer os fios que tece a singularidade da sua trajetória existencial e da pesquisa de doutorado, ora transformada em livro. Ao nos colocarmos/realizarmos o movimento de ouvir as Confissóes Alvorecentes, adentramos numa trama textual

\footnotetext{
${ }^{1}$ Sobre o autor: Eduardo David de Oliveira (Duda) é Doutor em Educação Brasileira pela UFC; Mestre em Antropologia Social pela UFPR; Especialista em Culturas Africanas e Relações Interétnicas na Educação Brasileira; Graduado em Filosofia pela UFPR. É Professor adjunto da Faced-UFBA; Ativista do Movimento Social Negro; Presidente do IPAD BRASIL. É iniciado na Tradição de Ifá.
} 
que solicita mais que a razão para ser percorrida. Uma trama que convida/mobiliza todos os sentidos. Assim, ouvimos a um só tempo os ecos da infância do menino Eduardo e da própria pesquisa de doutorado.

Mergulhando no universo lúdico da infância, Eduardo Oliveira conjuga realidade e fantasia, e brincando de mostrar, esconde sua infância. Joga sobre ela o véu do segredo, do mistério. O mistério perpassa toda a obra. Ele desenrola-se desde a primeira parte do texto até a última palavra do livro. Ladeia o texto o tempo todo. De fato, o autor nos traz o mistério como uma grande senha de leitura, a magia que ao insinuar mostrar, na verdade esconde.

Após as confissões que apontam a sedução como um grande itinerário da obra, a narrativa anuncia-se sem começo e sem fim. Pode-se fazer a leitura desde onde se desejar. Desde qualquer tempo/espaço, pois é a experiência do corpo que dará o sentido. Assim, importa que seja lido com o corpo, com os sentidos.

Na dinâmica do livro chega-se à primeira parte: Do movimento - Corpo. Nela encontramos os seguintes subcapítulos. Na sombra do cajueiro; escritos do dia; escritos da noite e corpo. Neste momento o corpo e o movimento são singulares e estruturantes ao mesmo tempo na construção narrativa.

Na Sombra do Cajueiro o autor nos apresenta o grande Xamã Norval Cruz. Apresenta também a Tempo Livre: Espaço de consciência corporal, criado e coordenado por Norval. Na Tempo Livre o autor irá (des)construir e (re)construir seu próprio corpo. Será possível fazer um corpo se movimentar nas páginas de um livro? Eduardo Oliveira abre a possibilidade para nos movimentarmos na zona de um corpo imanente.

O corpo que se movimenta nas páginas de Filosofia da Ancestralidade não é um corpo metafísico (se é que isso é possível), antes, é um corpo dilatado e enriquecido no espaço de sua contiguidade ancestral da experiência negra no Brasil. Este movimento permite que narrando sua experiência corpórea, Eduardo diga da experiência corporal de um coletivo - os afro-brasileiros. Assim, nos planos da imanência eis que o autor nos apresenta seu corpo, e os nossos corpos negros como território de identidade cultural, social e histórica. Corpos de pujantes experiências milenares! 
A experiência é um vetor fundante em Filosofia da Ancestralidade. Pois, é a partir dela que Eduardo Oliveira propõe a produção de conceitos. As experiências nos levam ao encontro de um fazer filosofia que cria mundos, desde o encontro com uma filosofia que nasce do próprio solo. Aqui aparece o encontro do corpo com a ancestralidade que tecerá o tecido do livro. O mistério se mostra (ainda que continue mistério), a ciência se traduz em magia, é o ritual da inversão! A vertigem $e$ a inversão, o contexto e o universal. A dialética do movimento que tem a matriz africana reinventada, a matriz afro-brasileira delineando a leitura do mundo. A alteridade apresentando-se como "ponto de partida. Ética como filosofia. Educação como Sabedoria" (OLIVEIRA, 2007, p. 7).

O autor nos aponta a sabedoria existente no exercício de perceber as dobras que impelem a não separação do pensamento daquilo que sentimos, é o sentir/pensar de corpo inteiro. A teia-de-aranha é um retrato da cultura, é força e mistério, lente pra se perceber o mundo é "Uma simbiose dos sentidos que vai multiplicando metáforas e re-criando signos" (OLIVEIRA, 2007, p. 81). O seu desenho nos remete ao outro, pois é o outro que nos tece, ela, a teia de aranha, é em si um conceito de alteridade.

Segue-se o texto com o Corpo Ancestral, onde esse corpo num momento primeiro é chão. Visto que não é um conceito acabado, é movimento, e, assim provisório. Aqui o autor não faz mistério, declara o desejo pelo pensar desde o corpo e não sobre ele. E o corpo escolhido é o de matriz africana que está integrado na cultura brasileira $e$ afrodescendente, onde a diversidade, a integração $e$ a ancestralidade aparecem como fundantes. $\mathrm{O}$ corpo, ao mesmo tempo, em que é ancestralidade também é regido por ela e "a construção de um corpo ancestral é uma máxima pedagógica" (OLIVEIRA, 2007, p. 101).

Oliveira também nos chama atenção, afirmando da necessidade do estar atento para o que se vê, pois o significado atribuído ao corpo que se vê, que fala, pode esvaziá-lo, inclusive da referência ao seu território. O corpo define-se pelo seu contexto, e, este advém da experiência do corpo. Significado e Significante.

$\mathrm{Na}$ auto-poiéses do corpo negro entendemos que recuperar o corpo como produtor de sentidos é o endereço que o autor dá à sua obra. A Tempo Livre e a 
Capoeira Angola são então, seus territórios de experiência. É o lugar desde onde se faz a leitura do corpo, partindo dos seus próprios signos, uma vez que a experiência não fala por si, mas dentro de uma forma. O corpo forjado nestes territórios se confronta com o corpo produzido pela sociedade capitalista $e$ industrial. Para se forjar um corpo há que descontrui-lo! A desconstrução do corpo ocorre na encruzilhada. E, nesta, e para além desta, Exu é o dono do corpo, pois apenas ele constrói, desconstrói e reconstrói.

É esse paradigma de Exu, onde o corpo é tudo e cada parte que dá entrada à segunda parte que é feita de De estruturas e singularidades. Exu matiza com suas cores o texto neste momento. A inversão é uma dessas cores. Uma das inversões do livro é a quebra da linearidade em sua construção narrativa. Isto é, não é necessário iniciar a leitura a partir da primeira parte, e, seguir no movimento progressivo para compreender o que se deseja na construção do enredo do livro. Pode-se inverter a leitura, assim como se pode ler partes de cada parte, e, ainda assim compreender a proposta conceitual e experiencial de corpo com a qual Oliveira nos desafia. A narrativa é construída de dobras, rugosidades, e, fluxo!

A obra realiza uma inversão significativa no intento de criar um pensamento que produza sentidos acerca do pensamento da educação brasileira partindo desde a Gênesis africana. A gnose africana reinventada no Brasil é uma das bases de elaboração da filosofia da ancestralidade para criar um entendimento do pensamento brasileiro.

Neste sentido, se chega a algumas questões importantes presente no texto: como fazer filosofia sem negar o corpo? Seja ele biológico e/ou cultural? Como potencializar o contexto, pois é impossível negá-lo, mas também não reificar este contexto como um universal totalizante? Outra questão ainda: a tecnologia da encruzilhada, utilizada como um recurso conceitual nesta filosofia, não se limita às fronteiras de seu próprio território? A encruzilhada liga todos os pontos, é o encontro, mas com os limites das especificidades, das diferenças.

O conceito de encruzilhada interpela para a ética, e a filosofia da ancestralidade é uma filosofia que tem como uma de suas proposições ser uma "máquina de guerra" contra o racismo no Brasil, por isso, é antes de tudo uma 
ética. A filosofia da ancestralidade é máquina de guerra porque preenche uma lacuna empreendida pela manifestação do racismo, que é o epistemicídio. Isto é, a pouca presença de estudos a respeito das cosmovisões ameríndias e afro-latinoamericana. A epistemologia do racismo "nega o evidente: o continente latinoamericano é uma indústria indígena (em primeiro lugar!) e africana (a posteriori)." (OLIVEIRA, 2007, p. 185).

A produção de uma filosofia no Brasil com bases nas cosmovisões ameríndias e afro-latino-americanas é uma das questões imprescindíveis para a afirmação e manutenção de liberdades das etnias historicamente negadas. Para combater o racismo epistemológico Eduardo Oliveira busca criar uma filosofia condizente com o contexto. Por isso, a Filosofia da Ancestralidade dialoga no canto do Colibri e se comunica de maneira efetiva e integral com Exu.

Os dois personagens conceituais Exu e o Colibri são alguns dos protagonistas do mundo criado em Filosofia da Ancestralidade. O encontro da tradição ameríndia com o africano reifica a lógica de procurar dar ênfase ao contexto na construção da filosofia da educação brasileira. Entretanto, a Filosofia da Ancestralidade não nega os universais, mas este universal está subordinado diretamente à contingência. Não há universais fora do território! É o que nos lembra Oliveira.

A afirmação da lógica do lugar próprio é mediada pela filosofia do Colibri e por Exu, a Filosofia do paradoxo. Exu afirma ao mesmo tempo a estrutura e a singularidade. Ele é a singularidade e estrutura dos corpos como nos destaca o autor: "aquele que viola todos os códigos é o mantenedor, por excelência do código". (OLIVEIRA, 2007, p. 130). Na filosofia do Paradoxo os conceitos não se expressam em totalidade, mas em singularidades.

Ainda nos rastros de uma filosofia que brota do chão, a filosofia da ancestralidade se configura no encontro da ancestralidade do território africano com a tradição indígena. Esse momento do livro é nomeado de Filosofia do Colibri. Este para alçar voo, brota do solo, chamada de Geo-cultura. A filosofia é o discurso da cultura, que na perspectiva afro e ameríndia brota do chão. E esse discurso aparece como uma ética, sendo assim, a ética é uma afirmação do 


\section{Revista Sul-Americana de Filosofia e Educação - RESAFE}

território. Não há universais para além do território. O contexto é a categoria que define se o sentido inferido acerca do real produz realidade ou não. A cultura é contexto. Por isso a lógica do lugar próprio, nessa perspectiva, é imprescindível à afirmação do território, para não reificar o etnocentrismo europeu.

O encontro das tradições (africana, latino-americana) faz com que a filosofia da ancestralidade seja uma filosofia que interpele para uma ação, a filosofia da ancestralidade pode ser entendida como uma ética que tem desdobramento imediato na política. A partir do momento em que se compreende a luta política como um movimento atrelado ao fazer filosófico em destaque, se percebe algumas categorias conceituais tais como a subjetividade, a ideologia, o imaginário e a criatividade como importantes para as populações africanas e seus descendentes. Isto é, a recriação da matriz africana em território brasileiro é revivida e reinventada desde o mito e o corpo.

A afirmação do parágrafo anterior pode ser constatada no capítulo do livro intitulado Semiótica do Encantamento, onde é feita uma leitura da semiótica desde a capoeira angola. A partir do corpo, do mito e de algumas categorias do próprio vocabulário da capoeira, tais como, ginga, movimento, Eduardo Oliveira entende a capoeira angola como um regime semiótico de leitura de mundo.

A recriação de mundos é potencializada também a partir do imaginário e da criatividade. E em Filosofia da Ancestralidade, o autor, ambiciona potencializar o imaginário afrodescendente a partir da história e cultura de matriz africana. Este virar-se, e, dobrar-se sobre a cultura afrodescendente, visa privilegiar a história contada a partir de uma perspectiva própria aos afrodescendentes. $\mathrm{O}$ autor foge do registro em negativo dos afrodescendentes - como vítimas, inferiores, etc. Antes, nas 330 páginas do seu livro, Eduardo apresenta a si, a Norval, e aos afrodescendentes como construtores de suas próprias experiências. E estas são positivas. Essa postura, também o combater o racismo, e busca criar realidades outras. A filosofia da ancestralidade tem como atitude criar mundos e não apenas conceitos.

Para além da construção de conceitos, que é próprio da filosofia, é imprescindível a potencialização de criação de mundos. Pois "sonhar e criar 
mundos é um ato político fundante do filosofar" (OLIVEIRA, 2007, p. 110). Nesse sentido se compreende que a liberdade é o resultado desta ação. E a luta por liberdade é protagonizada pelos personagens conceituais que se confundem entre Exú, Colibri, os mandingueiros, Norval, o próprio autor e o agenciamento que é realizado com e no leitor. Este é chamado para a ação, o corpo inerte na leitura é convidado a passear pelas paisagens do Ceará, a andar no mato com o grupo da Tempo Livre, a dançar samba, reggae, a tocar junto com Naná Vasconcelos e a combater as injustiças sociais, raciais, em suas práticas cotidianas. O leitor é chamado para a ação.

Filosofia da Ancestralidade é uma obra de arte que educa a sensibilidade para dialogarmos com a dinâmica cultural africana reinventada no território brasileiro, no nosso cotidiano. E, a partir disso, criarmos categorias analíticas para produzir sentidos na filosofia brasileira, com intento de ampliar e manter as liberdades dos afrodescendentes no território brasileiro.

O agenciamento realizado entre autor, leitor e a obra interpela para a ação, que tem como endereço o combate às desigualdades de oportunidade, e de acesso a bens sociais, por exemplo, entre os diferentes grupos étnicos presente na nossa sociedade multirracial brasileira. A filosofia da ancestralidade de matriz cultural africana é ética por unir o que a injustiça separou.

A leitura do livro é imprescindível para o entendimento da construção do pensamento brasileiro em diálogo com a dinâmica cultural africana $e$ afrodescendente. Assim, é uma leitura que realiza inversões a partir das categorias criadas do repertório cultural afrodescendente. Filosofia da Ancestralidade interpreta a dinâmica não apenas dos afrodescendentes no Brasil, mas da própria dinâmica do território brasileiro. 